\title{
REFLEXÕES SOBRE O DINHEIRO DE CRÉDITO EM MARX ${ }^{1}$
}

\author{
REFLECTIONS ON CREDIT MONEY IN MARX
}

\section{REFLEXIONES SOBRE EL DINERO DE CRÉDITO EN MARX}

DOI: http://dx.doi.org/10.9771/gmed.v11i3.35234

Ricardo Pereira de Melo²

Resumo: O objetivo principal do artigo é desenvolver a exposição dialética de Marx sobre o dinheiro de crédito e desvelar as potencialidades dessa categoria para compreender as relações fetichizadas do modo de produção capitalista. Para isso, pretende-se acompanhar a léxis de Marx sobre o desenvolvimento da categoria a partir do crédito comercial até o seu desenvolvimento em crédito bancário que está presente na seção V do Livro III de O Capital. A seção V, como o próprio Engels afirma, foi a parte mais difícil de organizar e editar, pois muitos textos estavam inacabados e os capítulos não possuíam uma ordem expositiva clara. Dessa forma, o artigo busca organizar uma proposta de apresentação de uma leitura conceitual do dinheiro de crédito exposto nessa seção de $O$ Capital.

Palavras-chave: Dialética, exposição, dinheiro, capital, dinheiro de crédito.

Abstract: The principal objective of the paper is to develop Marx's dialectical exposition on credit money and to unveil the potentialities of this category to understand the fetishized relations of the capitalist mode of production. For this, it is intended to follow Marx's lexis about the development of the category from commercial credit to its development in bank credit that is present in section V of Book III of Capital. The section V, as Engels himself states, was the most difficult part to organize and edit, since many texts were unfinished and the chapters did not have a clear expository order. Therefore, the article seeks to organize a proposal to present a conceptual reading of the credit money exposed in this section of Capital.

Keywords: Dialectic, exposition, money, capital, credit money.

Resumen: El objetivo principal del artículo es desarrollar la exposición dialéctica de Marx sobre el dinero de crédito y desvelar las potencialidades de esa categoría para comprender las relaciones fetichizadas del modo de producción capitalista. Para ello, se pretende acompañar la léxis de Marx sobre el desarrollo de la categoría a partir del crédito comercial hasta su desarrollo en crédito bancario que está presente en la sección V del Libro III de El Capital. La sección V, como el propio Engels afirma, fue la parte más difícil de organizar y editar, pues muchos textos estaban inacabados y los capítulos no tenían un orden expositivo claro. De esta forma, el artículo busca organizar una propuesta de presentación de una lectura conceptual del dinero de crédito expuesto en esa sección de El Capital.

Palabras clave: Dialéctica, exposición, dinero, capital, dinero de crédito.

\section{Introdução}

O dinheiro de crédito desenvolvido por Marx, especialmente na seção V do Livro III de O Capital, é a categoria filosófica relacionada à constituição do moderno sistema de crédito e apresenta-se como um importante conceito para explicar as diversas formas de circulação no modo de produção capitalista. Podese afirmar, seguindo as importantes contribuições de Klagsbrunn (1992) e Germer (1997; 2001; 2010), que o dinheiro de crédito é a forma de circulação preponderante no capitalismo desenvolvido ${ }^{3}$. Dentre as diversas formas de dinheiro de crédito, destacam-se as letras de câmbio, cheques, ordens de pagamentos, 
transferências interbancárias, cartões magnéticos dos bancos, notas bancárias e os depósitos em conta corrente nos bancos (GERMER, 1997, p. 6).

Com o desenvolvimento do modo de produção capitalista, o sistema de crédito é amplamente potencializado, auxiliando na circulação do valor-capital e, do mesmo modo, aparecendo o dinheiro de crédito na circulação como o principal "signo da circulação creditícia". Nesse sentido, o dinheiro de crédito nas suas diversas formas que aparecem na circulação é o meio mais adequado e necessário para atender as exigências de valorização do capital. $\mathrm{Na}$ forma aqui considerada por nós, o crédito comercial, funciona como um sistema de compensações recíprocas entre credor-devedor.

O objetivo desse artigo é mostrar como as potencialidades do sistema de crédito e do dinheiro de crédito analisado por Marx na seção V do Livro III de O Capital possui sua gênese (Der Ursprung) na circulação do crédito comercial. Abstraindo-se a ligação do sistema de crédito com o crédito bancário e também estatal, Marx começa do modo de apresentação (Die Darstellungsweise), portanto, sua análise do sistema de crédito desvenda a circulação do crédito meramente comercial ${ }^{4}$. Por fim, apresenta-se a relação originária existente entre o dinheiro de crédito puramente comercial com o capital bancário.

\section{Abstração e pressuposição da categoria dinheiro de crédito}

A circulação creditícia tem origem na determinação do dinheiro enquanto meio de pagamento sem, no entanto, confundir-se com ela, pois o dinheiro de crédito (das Kreditgeld) que surge na circulação capitalista exerce as funções de dinheiro e capital. Todo o rigor teórico de Marx em examinar a categoria dinheiro na primeira seção de O Capital, além de inúmeras páginas dedicadas nos Grundrisse de 1857/1858 e na Contribuição à Crítica de 1859, mostra a preocupação essencial do autor em demostrar a constituição do "dinheiro enquanto dinheiro" ou "dinheiro enquanto tal", e dessa categoria derivar as contradições do dinheiro de crédito. Por mais que Marx mencione o desenvolvimento do sistema de crédito no capítulo 3 do Livro I, ele precisará desenvolver todas as categorias do capital para se chegar a categoria dinheiro de crédito e as suas formas de circulação até chegar à constituição do capital bancário.

O duplo caráter do dinheiro de crédito manifesta-se pela forma como o capital de empréstimo movimenta-se na circulação capitalista como um todo. Conforme a posição que o dinheiro de crédito se encontra no processo global de produção capitalista, ele exerce uma determinação diferente, isto é, de funcionar ora como dinheiro, ora como capital. Então, podem-se distinguir duas etapas: primeiro, quando o crédito medeia à metamorfose da mercadoria, ou seja, $\mathrm{M}-\mathrm{D}$, o dinheiro de crédito simplesmente funciona como dinheiro enquanto meio de pagamento, facilitando a transação entre o comerciante e o consumidor final; segundo, quando o crédito medeia a compra de meio de produção, $\mathrm{D}-\mathrm{M}$, o dinheiro de crédito funciona como capital, transformando dinheiro em mercadoria para os capitalistas no processo de produção. Conforme Germer:

A sua derivação do dinheiro reconhece-se pelo fato de o dinheiro de crédito ter origem na função de meio de pagamento, e de ser essencialmente uma categoria da esfera da circulação, na qual substitui o dinheiro, realizando as suas funções de meio de circulação e de pagamento. A sua derivação do capital está clara no fato de ser ele produzido pelo 
sistema de crédito gerado pelo desenvolvimento do capitalismo a partir das relações de crédito comercial e bancário entre capitalistas (GERMER, 1997, p. 5).

Conforme Germer (2010, p. 130), o crédito comercial já expressa uma relação entre credordevedor na circulação simples de mercadorias, na função de meio de pagamento do dinheiro. O sistema bancário e o crédito propriamente capitalista estão pressupostos (Die Voraussetzungen) na exposição de Marx, tanto no Livro I e II quanto ainda no início do Livro III de O Capital. O crédito comercial antecede, lógico e historicamente, o desenvolvimento do sistema de crédito; no caso particular da circulação simples, o crédito comercial realiza as trocas pelo diferimento de pagamentos, sem que o dinheiro-ouro ou moeda, apareçam na circulação. Entretanto, na circulação simples, o crédito comercial não há pagamento de juros, pois a categoria juro faz parte do componente da circulação do capital e não do simples dinheiro ${ }^{5}$. A categoria dinheiro de crédito (das Kreditgeld) será analisada conceitualmente apenas na Seção V do Livro III, depois que Marx expõe as contradições do capital nos seus diversos níveis de entendimento. Agora, com o sistema de crédito e a supremacia da circulação do capital, o crédito comercial se potencializa nas relações econômicas.

A circulação do dinheiro de crédito efetua-se, no caso do crédito comercial e pressupondo todas as outras formas de crédito, em sua maioria entre capitalistas industriais e comerciais, como por exemplo na troca de matérias-primas, aluguéis, prédios e equipamentos. A garantia do pagamento desses títulos é a transformação do capital-mercadoria em dinheiro para o endosso dos títulos. Assim, as operações de crédito se espalham dominando toda a circulação.

Todas essas promessas de pagamento entre capitalistas são reunidas por Marx na categoria geral letras de câmbio ${ }^{6}$. Essas letras circulam como meios de circulação (currency), pois são utilizadas como mecanismo de compra e venda de mercadorias, mediante ao endosso desses títulos. Todo processo foi mediado pelo crédito, sem que o dinheiro real (papel-moeda e ouro) surgisse na circulação. Essas diversas operações são realizadas conforme a confiança que todos possuem no dinheiro de crédito.

A letra de câmbio pode circular momentaneamente como meio circulante (currency), mas essa função, por ter um prazo de vencimento dado, seu aceite deve-se a confiança na promessa de pagamento dos agentes. Pode-se afirmar que o crédito comercial representado pela letra de câmbio possui uma circulação bastante restrita entre comerciantes e estes com outros capitalistas, mas constitui metodologicamente, o ponto de partida para o entendimento dialética do dinheiro de crédito.

A circulação das letras cresce conforme o volume dos negócios realizados entre capitalistas, independente do crédito bancário. De certa forma, o desenvolvimento do processo de produção cria e amplia o crédito e, ao mesmo tempo, o crédito expande a produção capitalista. Enquanto as letras de câmbio não são compensadas, elas são instrumentos de circulação capitalista e constituem o alicerce do dinheiro de crédito. As transações realizadas na base do crédito comercial entre industriais e comerciantes constituem a base do desenvolvimento do sistema de crédito.

Dessa forma, as letras de câmbio tornam-se mais um componente da circulação e de enorme aceitação nas principais praças de negócios. Esse enorme montante de crédito é garantido pelos bancos 
comerciais com base em suas reservas em notas bancárias de outros bancos, títulos diversos, papel-moeda estatal e ouro.

Até o vencimento, as letras de câmbio funcionam realmente como dinheiro na circulação, pois sem elas as mercadorias não se transformam em dinheiro propriamente dito. Os comerciantes e industriais trocam entre si promessas futuras de pagamentos e, depois de um determinado período, as letras de câmbio se extinguem por compensação entre débitos e créditos. Assim, as diversas mercadorias circulam sem a necessidade do papel-moeda estatal ou dinheiro metálico, apenas promessas de compensações futuras. A circulação do dinheiro de crédito baseado em "signos de crédito" (Kreditzeichenen) cria-se uma circulação independente e autônoma da circulação simples, uma circulação sem lastro em ouro e sem materialidade nas relações sociais.

O simples dinheiro descrito por Marx no capítulo 3 do Livro I está ligado diretamente à plena conversibilidade do dinheiro-mercadoria. O dinheiro de crédito exerce essa função sem a necessidade de ser mercadoria-ouro e, ao mesmo tempo, exerce a função de capital meramente virtual. Como bem nota Klagsbrunn (1992, p. 595) “o dinheiro de crédito não está amarrado quantitativamente à disponibilidade de ouro (que seria uma barreira natural inaceitável)". Para Marx, caracterizando o dinheiro de crédito, afirma:

Essa última forma de crédito salta aos olhos do leigo como especialmente importante, primeiro, porque essa espécie de dinheiro de crédito sai da mera circulação comercial para a circulação geral e funciona aqui como dinheiro (Die leţtere Form des Kredits erscheint dem Laien besonders frappant und wichtig, erstens weil diese Art Kreditgeld aus der bloßen Handelszirkulation heraus in die allgemeine Zirkulation tritt und hier als Geld fungiert) (MARX, 1983a, p.304; MARX, 1983c, p. 417 - negritos RPM).

Marx verifica que o meio de circulação (currency) é completamente subsumido pela circulação creditícia, sem abolir as bases da circulação simples. O debate na Inglaterra no período de 1797-1857 entre governo e banqueiros deve-se aos rumos dos negócios praticados por essas letras e a conversibilidade plena em ouro 7 . Ao analisar as Letter on the Currency de 1840, Marx retira esse importante depoimento de um banqueiro de Yorkshire:

As letras de câmbio são um componente da circulação que é de montante maior que os demais em conjunto [...] Essa enorme superestrutura de letras de câmbio repousa sobre a base constituída pelo montante das notas de banco e do ouro; e quando, no curso dos acontecimentos, essa base se estreita demais, sua solidez e mesmo sua existência correm perigo (MARX, 1983a, p. 301-2; MARX, 1983c, p. 414).

O papel-moeda de curso forçado pode ser perfeitamente controlado pelos governos, estipulando uma determinada quantia na circulação ajustando-se aos preços das mercadorias e ao volume dos negócios. Contudo, as letras de câmbio, como relata o banqueiro de Yorkshire, "não podem ser postas sob controle", pois são negócios privados entre comerciantes e industriais que adiantam suas compras com garantias futuras de pagamentos.

Além disso, várias letras são emitidas de maneira fictícia, sem relação com as compras reais, apenas alterando as datas de vencimentos. Então, parte desses títulos comerciais é emitida não contra transações de mercadorias reais, mas para saldar dívidas antigas. Essas letras são emitidas pelos bancos privados com novas datas de vencimento, retirando da circulação, as letras de câmbio antigas ou, mesmo, adiantando os papéis fictícios antes da mercadoria entrar na circulação; portanto, lança-se um título para pagar outro título 
com o vencimento prorrogado. Essas letras de câmbio com vencimento diferido não possuem como contrapartida uma transação entre produtores e comerciantes, mas sua existência é puramente fictícia (fiktives Kapital.

Os milhares de pagamentos liquidados diariamente na câmara de compensação dos bancos ultrapassam as reservas diárias de dinheiro real. O dinheiro de crédito (no caso, apenas o crédito comercial analisado neste artigo) é decisivamente um meio de circulação capitalista, desenvolvido pela própria necessidade (Die Notwendigkeit) de circulação do valor. Quando ocorre um aumento generalizado dessas letras em relação a circulação monetária, o sistema bancário como um todo entra em crise, e os credores correm para descontar seus títulos por dinheiro real, e a abundância de crédito coloca os bancos numa crise de confiança. O crédito, segundo Tooke citado por Marx, "em sua expressão mais simples, é a confiança”, contudo, sua base é puramente fictícia e fantasiosa.

\section{Contradição e crise da circulação do dinheiro de crédito}

Conforme analisado no tópico anterior, o crédito comercial representa ordens de pagamentos futuros entre capitalistas e consumidores em geral no ciclo reprodutivo do capital. As letras de câmbio são a expressão mais peculiar da circulação creditícia e, portanto, são uma forma particular do dinheiro de crédito na circulação do comércio de mercadorias. Abstraindo, por enquanto, o crédito bancário que representa outro momento da exposição, as letras de câmbio circulam entre comerciantes e industriais funcionando como dinheiro enquanto meio de pagamento. Vender e comprar mercadorias com pagamento diferido, mediante endosso entre credor e devedor, é a atividade econômica capitalista por excelência.

Quando um fiandeiro A, no exemplo utilizado por Marx, tem que pagar uma letra de câmbio ao credor-exportador de algodão B e, este por sua vez, precisa pagar ao importador C. Se o importador C exporta também fios de algodão, pode comprar do fiandeiro A com letras, e este pode pagar ao credor de algodão B com a própria letra. Neste caso, as letras de câmbio circulam realmente como dinheiro, dispensando o papel-moeda e o dinheiro metálico na transação.

Para acontecer a liquidação da letra de câmbio é necessário, prioritariamente, que M - D se realize. Se o fiandeiro A vendeu fio a $\mathrm{C}$ e, $\mathrm{C}$ não transformou a mercadoria fio em dinheiro no mercado mundial, não poderá pagar ao fiandeiro e, consequentemente, não acontecerá o pagamento ao credor de algodão B. Então, os pagamentos dependem da fluidez da metamorfose da mercadoria em dinheiro. Para evitar a possibilidade de crise, pois "a capacidade de pagar de um depende ao mesmo tempo da capacidade de pagar do outro", o sistema de crédito garante uma determinada reserva, caso aconteça entretempo entre os refluxos dos saldos a pagar. O produtor saldará sua dívida ao negociar sua mercadoria, executando a letra.

Esse ciclo descrito acima, "do plantador de algodão até o fiandeiro de algodão e vice-versa, só pode constituir uma exceção e não pode deixar de ser sempre interrompido em muitos pontos" (MARX, 1983b, p. 22). Caso o fiandeiro A precise pagar outra letra vencida a D, antes de receber a letra do exportador de algodão C, o ciclo é interrompido e abre a possibilidade de crise. Esses infortúnios da circulação são compensados com as eventuais reservas disponíveis que os capitalistas possuem. Dessa forma, a circulação 
das letras não elimina a necessidade das transações em dinheiro real, até porque o fiandeiro precisa pagar salário e imposto com dinheiro em espécie, além é claro, de dívidas casuais no processo reprodutivo ${ }^{8}$.

Esse dinheiro de reserva depende da riqueza de cada capitalista e os ramos de produção que cada um se encontra. Assim, para Marx, "quanto maior o prazo de vencimento das letras de câmbio, tanto maior tem de ser o capital de reserva, e tanto maior é a possibilidade de uma diminuição ou retardamento do refluxo por queda de preço ou saturação dos mercados" (MARX, 1983b, p. 22). A dilatação do tempo dessas letras aumenta também a especulação desses títulos, pois o pagamento das letras de câmbio depende do preço da mercadoria no futuro, algo puramente incontrolável e imprevisível.

A especulação com títulos torna-se uma atividade lucrativa, pois a compra e venda das letras, dependem das previsões de alta ou baixa dos preços futuros das vendas de determinadas mercadorias. Assim, como afirma Marx, "o elemento especulativo deve dominar cada vez mais as transações (das spekulative Element mehr und mehr die Transaktionen beherrschen muß)" (MARX, 1983b, p. 22; MARX, 1983c, p. 496).

Enquanto o processo reprodutivo mantém-se tranquilo, as letras circulam de mão em mão e o seu refluxo é garantido no prazo determinado. A produção e reprodução do capital ampliam o sistema de crédito, e o crédito amplia a produção. O desenvolvimento do sistema de crédito garante a unidade contraditória entre a produção e o consumo.

Quando a produção é interrompida, as vendas reduzem drasticamente e os estoques de produção aumentam. O capital fixo fica desocupado e as demissões se alastram. Uma teia do processo reprodutivo global é rompida e uma série de metamorfoses não é realizada. Dessa forma, os capitalistas correm para trocar suas letras de câmbio por dinheiro seguro e a crise se alastra por toda a economia capitalista. É nesse momento que o crédito se contrai.

As letras de câmbio não são compensadas e a crise aparece na circulação, primeiro como uma crise comercial e, posteriormente, como uma crise de crédito. "A confiança na fluidez do processo de reprodução está quebrada" (MARX, 1983b, p. 23; MARX, 1983c, p. 497). A crise aparece na circulação como uma desproporção entre produção e consumo entre os próprios capitalistas nos diversos ramos econômicos que estão interligados no processo. Para Germer:

A inevitabilidade da crise onde predomina o sistema de crédito decorre do fato de que,
uma vez que o crédito substituiu o dinheiro na circulação, é no crédito que está baseada
toda a trama de relações entre capitalistas, formando cadeias de compromissos sucessivos
vinculados um ao outro e uma imensa rede de cadeias entrelaçadas, de modo que a
liquidação de um débito depende da liquidação do precedente e assim por diante. Assim,
quando os pagamentos começam a interromper-se em um ponto, todo o fluxo se
interrompe e a crise é inevitável (GERMER, 2010, p. 143).

A quebra da confiança significa que fica mais difícil conseguir crédito para comprar mercadorias. O período em que se instaura a crise, a exigência para conseguir crédito para comprar novas mercadorias fica maior; mas é particularmente a necessidade dos capitalistas para saldar seus credores que torna a crise muito mais grave. Todos querem vender suas mercadorias estocadas a qualquer preço e se livrar dos títulos comerciais a qualquer custo. A taxa de desconto nos bancos chega ao seu máximo e o crédito (para saldar dívidas antigas) fica ainda mais escasso. 
Mas, no momento da crise:

Fábricas ficam paradas, matérias-primas se amontoam, produtos acabados abarrotam, como mercadorias, o mercado. Nada mais falso, portanto, que atribuir tal situação à falta de capital produtivo. Exatamente então tem lugar excesso de capital produtivo, em parte com relação à escala normal, mas momentaneamente contraída, da reprodução, em parte com relação ao consumo paralisado (MARX, 1983b, p. 24; MARX, 1983c, p. 497).

A classe operária fica desocupada e o consumo dos trabalhadores fica limitado, "pela circunstância de só serem empregadas enquanto puderem ser empregados com lucro para a classe capitalista" (idem). Contudo, não é pela escassez de capital produtivo que a sociedade capitalista entra em crise; somente, podese falar em crise de escassez quando ocorrem crises agrícolas generalizadas, faltas de matérias-primas ou desastres naturais. A razão da crise deve-se, de um lado, à superabundância de valores-capitais; e do outro lado, a miséria e a restrição do consumo das massas ${ }^{9}$.

Após a crise, os preços das mercadorias reduzem ao seu nível mais baixo e o capital produtivo paralisado reduz a massa monetária desembolsado com salários. Como consequência dessa retração, os meios de circulação são contraídos e acontece também uma redução na demanda por capital de empréstimo, seja para meio de circulação, seja para meio de pagamento.

Quando a economia se recupera e inicia-se a fase de prosperidade, a taxa de juros permanecerá baixa, mas acima do menor nível alcançado logo após a crise, e o crédito comercial volta a ser demandado regularmente. A grande oferta de capital emprestável à juro baixo e a facilidade de conseguir crédito leva novamente a ampliação do capital industrial: o ciclo do crédito recomeça novamente. Todo esse movimento ilustra perfeitamente o pensamento de Marx sobre as crises cíclicas da reprodução do capital e seus reflexos na totalidade da luta de classes.

\section{A gênese do sistema avançado de crédito em Marx e a potência de "fazer dinheiro" ou o desenvolvimento do dinheiro de crédito na totalidade da circulação capitalista}

O sistema de crédito se desenvolve na base dos comerciantes de dinheiro e nas atividades ligadas a guarda dos fundos de reserva dos homens de negócios, operações técnicas de cobrança e pagamento e o comércio de barras no mercado mundial ${ }^{10}$. Ao mesmo tempo em que se desenvolve logicamente a circulação do dinheiro de crédito cria-se também todos os mecanismos sistêmicos do crédito. Com isso, desenvolvese conjuntamente outro aspecto do sistema de crédito que é da administração do capital monetário emprestável ou capital portador de juros que, segundo Marx, essa atividade torna-se um "negócio especial".

O desenvolvimento do comércio de dinheiro tende a concentrar-se nos grandes capitalistas bancários. Eles seriam na análise de Marx, os grandes administradores gerais do capital monetário emprestável portador de juros ${ }^{11}$. A função do banco consiste em concentrar grandes massas de capital monetário a qualquer momento e também concentrar as informações dos mutuários.

Dessa forma, o capitalista bancário é cobrador de todos os outros capitalistas. Tanto o capitalista industrial quanto o capitalista comercial realizam pagamentos de diversas espécies no banco. Todo esse fundo, por meio dos bancos, torna-se capital emprestável. Esse fundo bancário sempre é reduzido ao limite 
mínimo e a maior parte é emprestada, funcionando como capital portador de juros. O capital não pode ficar ocioso no fundo de reserva dos bancos, ele precisa sempre circular.

O capital emprestável dos bancos é constituído também por depósitos dos capitalistas monetários, "que lhes cedem a tarefa de emprestá-los". Assim, pequenas somas de capital incapazes de atuar individualmente, agora unificadas são grandes massas e "constituem assim um poder monetário" 12.

Por serem câmaras de compensação de cheques e de ordens de pagamentos, as letras de câmbio afluem para os bancos como pagamento de um capitalista e reserva para outro. Assim, os capitais monetários dos comerciantes e industriais fixam-se em um fundo comum sob a gerência dos bancos. Esse capital é reserva para os capitalistas industriais e comerciantes, mas é capital potencial para os bancos ${ }^{13}$.

O dinheiro de crédito tem plena aceitação na circulação capitalista. Enquanto o dinheiro-ouro e o papel-moeda escasseiam-se se na circulação, as notas bancárias criadas pelos bancos circulavam regularmente entre os clientes do próprio banco emissor e também entre bancos.

A circulação do dinheiro de crédito como "signo de circulação creditícia" substitui completamente a necessidade do meio de circulação (currency) nas transações capitalista. Dessa forma, os bancos guardam como fundo de reserva o dinheiro real, economizando-as na circulação e, com isso, faz circular o dinheiro de crédito mediante a transferência de crédito entre seus clientes que liquidam suas transações em prazo determinado. O dinheiro enquanto tal não gera nenhum rendimento, mas o capital de empréstimo gera juros e taxas aos bancos. Nas mãos do banqueiro, o capital monetário funciona como capital portador de juros.

As letras de câmbio analisadas por Marx até os primeiros capítulos da seção V de Livro III de $O$ Capital é a base do empréstimo meramente comercial. Mas o crédito que os bancos dão é de diversas formas, assim citados por Marx: a) letras de câmbio contra outros bancos; b) cheques contra os mesmos; c) aberturas de crédito da mesma espécie; d) notas bancárias dos bancos emissores. Essa última forma de crédito, como afirma Marx, "salta aos olhos do leigo", porque a nota bancária - que é uma letra de câmbio contra o banqueiro pagável em qualquer momento - sai da circulação comercial para a circulação como um todo, funcionando como dinheiro e substituindo o papel-moeda ou dinheiro metálico nas funções de dinheiro na circulação.

A nota bancária ou o bilhete do banco é o título que o banco (no caso, banco comercial) emite em troca de letras de câmbio. Para a função de meio de circulação, a nota bancária tem a circulação mais ampla que a letra de câmbio e, em contrapartida, os bancos recebem um pagamento para realizar esse tipo de atividade, de ser capital comércio de dinheiro ${ }^{14}$. O bilhete de papel constitui um direito de parte da liquidez dos bancos.

As notas bancárias emitidas pelos bancos representam um meio de pagamento de aceitação geral e também um mecanismo de circulação baseado no crédito bancário. A plena conversibilidade das notas bancárias privadas faz com que as notas circulem normalmente ao lado do dinheiro metálico e do papelmoeda. No ciclo de prosperidade, a confiança nessas notas bancária - "signo circulante de crédito (ein zirkulierendes Kreditzeicichen)" - generaliza-se e as suas transações costumam ser regulares. A facilidade com que elas são descontadas nos caixas dos bancos nas praças financeiras perpetra aos bancos a proeza de "fazer dinheiro" 15 . 
Os bancos então possuem duplo negócio: facilitar a circulação do capital e promover a circulação dinheiro como meio circulante (currency). Nota-se, quando Marx diz que os principais bancos emissores dos países emitem notas tendo como contrapartida o próprio crédito nacional, ele já está mostrando o futuro dos principais bancos centrais que estarão em formação mais ou menos neste período. As leis bancárias de 1844 tornam o Banco da Inglaterra legalmente o banco emissor porque ele já era na prática o principalmente credor do governo britânico. Quanto maior a aceitação de um banco por sua nota bancária, maior é o seu poder de "fazer dinheiro", de fazer dinheiro estatal inconversível.

A nota bancária inconversível que realmente circula é dinheiro, dinheiro de crédito, que representa as funções do dinheiro como meio de pagamento. Dessa forma, o dinheiro de crédito circula sem lastro e o seu movimento é regido pelas leis de funcionamento do sistema de crédito. Entretanto, a determinação do dinheiro (simples dinheiro analisado por Marx no capítulo 3 do Livro I) enquanto meio de pagamento é regido pelas leis da circulação simples, sendo o capital apenas seu pressuposto; já o dinheiro de crédito, o capital é resultado do sistema de crédito e determinado por este.

O crédito bancário potencializa as trocas capitalistas fazendo com que o banco realize diversas outras formas de transações listadas por Marx, tais como: a) letras de câmbio contra outros bancos; b) cheques contra os mesmos; c) aberturas de crédito da mesma espécie; d) as próprias notas do banco (banco emissor). A nota bancária (atualmente, o dinheiro particular criado por um banco ou todos os instrumentos financeiros criados, desde transferências eletrônicas e doc's bancários) é apenas uma letra de câmbio contra o banqueiro pagável ao portador a qualquer momento, e pelo qual o banqueiro substitui a letra de câmbio particular ${ }^{16}$. Pode-se afirmar que, segundo Marx, a nota bancária e o sistema avançado de crédito possuem sua gênese do desenvolvimento do próprio crédito comercial (circulação da letra de câmbio).

O sistema de crédito torna-se uma alavanca importante também para o crescimento do negócio especulativo. A preocupação dos economistas segundo os relatórios citados por Marx era o aumento considerável de capital monetário. As economias ficavam sujeitas as crises periódicas pela falta de aplicação do capital monetário excedente. Para combater a pletora do capital, a absorção do capital excedente deve ser feita, especialmente, pela absorção do capital monetário emprestável pelo Estado, por meio da dívida pública. O papel da dívida pública como mecanismo de absorção de capital torna-se estrutural com a acumulação do capital. O Estado aperfeiçoa-se nesse mecanismo para esterilizar a febre especulativa provocada pela enxurrada de capitais desocupados no mercado.

Os circuitos de absorção do capital monetário pelo Estado são a principal forma de circulação capitalista na pirâmide financeira do capital. Dessa forma, o Estado garante a remuneração estável do capital, mantendo as taxas de juros positivas. Com o desenvolvimento do sistema de crédito favorece o deslocamento de massas de capital emprestável, aumentando consideravelmente o processo de concentração e centralização do capital. Estabelece-se uma necessidade cada vez mais importante da presença do Estado.

A circulação creditícia ultrapassa consideravelmente a circulação monetária, como já destacara os relatórios bancários estudados por Marx em O Capital. Devido à circulação autônoma que executa o dinheiro 
de crédito, a série de transações realizadas por esse signo de circulação, não passa no registro dos bancos, o que torna o comércio e a especulação uma atividade primordial desse "negócio especial".

A expansão do dinheiro de crédito é sinal de acomodação do aumento dos lucros e da atividade industrial. Ao mesmo tempo, essa expansão cria-se uma série de facilidade para se conseguir financiamento para saldar dívidas e adiantamentos diversos. O dinheiro de crédito fácil é a causa da febre especulativa. A consequência imediata da crise do crédito relatado por Marx a partir de 1857 foi a elevação das taxas de juros e um novo período revolucionário na Europa que culminará na própria organização da I Internacional e do levante da Comuna de Paris. Depois da prosperidade, vem a crise e, com ela, o fantasma da revolução.

\section{Referências:}

BENOIT, H. Sobre a crítica (dialética) de O Capital. Revista Crítica Marxista, nº 03, São Paulo: Xamã, 1996.

CHAGAS, E. F. O método dialético de Marx: investigação e exposição crítica do objeto. Sintese. Belo Horizonte, v. 38, p. 55-70, 2011.

DE BRUNHOFF, S. A Moeda em Marx. São Paulo: Paz e Terra, 1978.

FULDA, H. F. Tese para a dialética como método de exposição (no "Capital" de Marx). Revista Crítica Marxista, n 45, São Paulo: UNESP, 2017.

GERMER, C. M. O Dinheiro de crédito e as funções do dinheiro no capitalismo. In: Anais do XXV Encontro Nacional de Economia. Recife: ANPEC - Associação Nacional de Pós-Graduação em Economia, v. $1,1997$.

Dinheiro e dinheiro de crédito no capitalismo avançado. Revista Ensaios FEE. Porto Alegre, v. 22, n.1, p. 205-228, 2001.

O Capital bancário e a relação indústria-bancos na teoria de Marx. Revista Análise Econômica (UFRGS), v. 28, p. 129-158, 2010.

HILFERDING, R. O Capital financeiro. São Paulo, SP: Nova Cultural, 1985.

KLAGSBRUNN, V. H. Considerações sobre a categoria dinheiro de crédito. Revista Ensaios FEE. Porto Alegre, v. 13, n.2, p. 592-615, 1992.

MARX, K. O Capital. Volume 3: O processo global da produção do capital. Tomo 1. Trad. Regis Barbosa e Flávio R. Kothe. São Paulo: Abril Cultural, 1983a.

O Capital. Volume 3: O processo global da produção do capital. Tomo 2. Trad. Regis Barbosa e Flávio R. Kothe. São Paulo: Abril Cultural, 1983b.

Das Kapital. MARX, Karl; ENGELS, Friedrich: Werke (Band 25). Berlin: Dietz Verlag, 1983c.

MELO, R. P. A Dialética do capital a juros em Marx. In: SILVA, M. S. (Org.). Ser e pensar, inícios. São Paulo: Todas as Musas, 2016.

MÜLLER, M. L. Exposição e método dialético em 'O capital'. Boletim SEAF-MG, n’ 2, Belo Horizonte, 1982.

\section{Notas:}

${ }^{1}$ Esse artigo é uma versão aprimorada do texto publicado nos Anais do IX Colóquio Internacional Marx e Engels realizado na cidade de Campinas/SP em 2018. Além disso, o atual artigo é parte modificada de minha Tese de Doutorado desenvolvida no Programa de Pós-Graduação em Filosofia da Universidade Estadual de Campinas (UNICAMP). 
2 Universidade Federal de Mato Grosso do Sul. Mestre e Doutor em Filosofia e professor do Mestrado Profissional em Filosofia da UFMS. ORCID: Email: ricardopdemelo@gmail.com

3 Os trabalhos pioneiros de Rudolf Hilferding (1985) e Suzanne De Brunhoff (1978) apesar de importantes para o desenvolvido da categoria marxista do dinheiro e do capital não levaram em conta o papel do método de exposição do autor de O Capital. Sobre a exposição dialética de O Capital, consultar os artigos MÜLLER (1982), BENOIT (1997), CHAGAS (2011) e FULDA (2017).

4 "Desse modo, os títulos de crédito comercial constituíram a forma primitiva do dinheiro de crédito" (GERMER, 2010, p. 131).

5 “Assim, o crédito comercial na sua origem não tem ligação com o crédito monetário e, portanto, não pressupõe o juro, que é uma categoria do capital portador de juros, ainda inexistente na circulação simples de mercadorias" (GERMER, 2010, p. 131).

${ }^{6}$ A escolha não é aleatória. Na Europa do século XIX, as letras de câmbio eram a forma predominante de circulação capitalista do comércio de mercadoria. Marx usa também o termo "dinheiro comercial".

7 "Isso não significa que o ouro não esteja na base, embora longínqua, passando por inúmeras mediações, de todo o complexo sistema monetário e creditício sobre o qual o capitalismo se constrói”" (KLAGSBRUNN, 1992, p. 596). E continua: "A relação do dinheiro de crédito com o metal precioso é que lhe dá, em última instância, sua base racional” (KLAGSBRUNN, 1992, p. 597).

8 Germer (2010, p. 137-143) discute sobre o papel das reservas monetárias no ciclo reprodutivo do capital

9 Para Marx, uma das principais causas que levaram a crise de 1857 foi a extraordinária superprodução dos mercados e a fraude ilimitada das letras de câmbio.

10 Percebe-se que, no plano expositivo dialético de Marx, já fora feito a análise da categoria capital comércio de dinheiro (Geldhandlungskapital) na seção IV do Livro III de O Capital.

${ }^{11}$ Sobre o capital portador de juros (Das qinstragende Kapital) consultar MELO (2016, p. 315-325).

12 Deixamos para futuros trabalhos o desenvolvimento da categoria capital bancário (Das Bankkapital) em Marx.

13 "Por isso, para o capital, a forma que o dinheiro assume, no geral, não é relevante; o que interessa é que sejam forma que permitam e agilizem o processo de valorização. Portanto, a exigência central é que o dinheiro seja meio de valorização e não reserva de valor" (KLAGSBRUNN, 1992, p. 597).

${ }^{14}$ É importante destacar as funções que os bancos exercem no sistema de crédito desenvolvido, que no âmbito desse artigo não serão analisadas.

15 "A nota bancária é um título de crédito que, podendo circular de modo bem mais generalizado, pode assumir funções de dinheiro - dinheiro de crédito - para um círculo mais amplo de pessoas do que a letra de câmbio. Isto porque ela é aceita como meio de circulação geral, com base no crédito de que goza o banco emissor" (KLAGSBRUNN, 1992, p. 605).

16 Os depósitos em conta corrente constituem a forma mais efetiva de circulação capitalista, pois os bancos criam novas somas de dinheiro - dinheiro de crédito - a partir dos novos depósitos, somas emprestadas e compensações recíprocas, todas elas alicerçadas no moderno sistema de política monetária guiado pelo Banco Central.

Recebido em: 23.01.2020

Publicado em: 20.04.2020 